\title{
A Study on Pragmatic Failures in Verbal Communication of Non-English Majors
}

\author{
Jia Kou \\ department of nursing, henan nursing vocational college, 455000, China.
}

\begin{abstract}
Non-English majors often have pragmatic failures in cross-cultural verbal communication, which leads to failure in smooth communication. Therefore, how to improve the pragmatic competence of non-English majors and avoid pragmatic failures is a serious challenge for current college English education. Based on the teaching practice, this paper analyzes the problems and causes of pragmatic failures in students' verbal communication, and puts forward relevant teaching Suggestions.
\end{abstract}

Keywords: pragmatic competence; Pragmatic failures; Speech communication; College English education.

\section{Introduction}

With the development of global integration, the exchanges and cooperation among countries and nationalities in the world are increasingly enhanced. In order to adapt to the rapid development of today's society, the ministry of education in the 2007 version of "college English curriculum requirements" explicitly put forward the goal of college English teaching is to develop students' English comprehensive application ability, especially listening and speaking skills, to make them in the future study, work and social activities can communicate effectively in English, at the same time to improve their ability of autonomous learning, improve the comprehensive cultural quality, to meet the need of social development in our country and international communication. It can be seen that language, as a tool of communication, plays an important role in the life of modern society. In order to comply with the development of The Times, college English teaching should not only cultivate students' language ability but also their pragmatic ability.

\section{Reasons for the Lack of Pragmatic English Ability and Weak Consciousness of Non-english Majors}

According to the chronological order, the development of pragmatics has undergone the following main process: the earliest publications of pragmatics owe to the research findings of Chomsky (Chomsky,1962). Chomsky thinks that competence includes grammar and pragmatic competence, but he pays more attention to grammar and keeps trying to find out more about it. Thomas defined pragmatic competence as the ability to use language properly in order to achieve a specific purpose and to understand discourse in context (Thomas,1983,p.94). He and Levinson also distinguished the differences between pragmatic competence and social pragmatic competence. But who should come first in grammar or pragmatics or what kind of dependency is there between them? According to Levinson (1983), pragmatics must precede grammatical elements in logical ordering. In addition, h.g. Widdowson (2000) proposed that capability should include two aspects, namely knowledge and ability. According to his opinion, pragmatic ability should also be composed of two parts, namely pragmatic knowledge and pragmatic ability. Therefore, when we talk about pragmatic competence, we should consider pragmatic knowledge. Only by mastering certain pragmatic knowledge and applying it in practice can we develop learners' pragmatic competence.

At present, there are many problems and deficiencies in the cultivation of students' comprehensive English ability in college English teaching. In teaching, teachers still overemphasize the importance of grammar and vocabulary but ignore the cultivation of communication skills. Students who love English as a language and study hard are only a small part of the students. Most non-English majors study English only to get a degree. Even if they pass the cet-4, cet-6, PETS and other English skills or grades, they only want to have a favorable condition when they graduate or get a job in the future. 
They only memorize words mechanically to pass the test and do exercises accordingly without realizing that English should be a subject to be learned as a practical application. This weak pragmatic awareness leads to the lack of pragmatic competence in non-English majors.

At the same time, from the bondage of the traditional teaching mode, a lot of non-English major students, although has the good grammar skills, able to communicate appropriately in the context of a certain, but because do not understand the cultural background, different from our own often leads to people unable to express himself or hearer embarrassing situations could not understand each other, resulting in the phenomenon of pragmatic failures in verbal communication.

\section{Analysis of Pragmatic Failures in Verbal Communication of Non-English Majors}

The first person to make a pragmatic failure was Jenny Thomas, a linguist at the university of Manchester in England

The main function of language is communication. However, many foreign language learners, who have a strong language ability, often fail to express their ideas correctly in cross-cultural communication. This phenomenon is known as Pragmatic failure. Thomas also divides pragmatic failures into two categories, namely Pragma linguistic failure and Sociodramas failure. The former is the pragmatic failure caused by the language itself, such as the expression of non-conformance with the language habits of native English people, the misuse of English expressions, or simply do not understand the correct expression of English, and the application of English according to the semantics and structure of the mother tongue. for example: "good morning, miss wang! "Good morning, Teacher Wang! "Good morning, Mr./Miss Wang! "Or" Good morning! The latter refers to the failure of language form selection in cross-cultural communication due to the lack of understanding of the cultural background differences between the two parties. For example: we helped a foreign friend do something when he said "Thanks a lot! "What should we say? The correct way to say It is "You are welcome." It is my pleasure! / My pleasure!", "Not at all.", "Don't mention it.", "it's nothing. "But in this context if you answer "Never mind! "Was wrong. "Never mind" is used to comfort the speaker when he or she has done something wrong, feels guilty, and asks forgiveness. This example is given on the premise that the foreign friends just want to express their gratitude for our help, and have done nothing wrong. It's not appropriate. At present, there are the following major pragmatic failures in verbal communication among non-English majors in Chinese universities:

\subsection{Misaddress}

Chinese students cannot address others correctly in cross-cultural communication. First of all, they do not know the Chinese name and English name order is the opposite, such as Peter Lee, we only need to call Peter, Lee is the last name. In addition, Chinese people often refer to their good friends as brothers or sisters. But for foreigners, the word "brother/sister" can only refer to people who are related to their parents.

\subsection{Wrong Salutation}

Chinese people are used to greeting their acquaintances with "have you eaten? "It's a way for us to show our care to each other. But foreigners can create ambiguities; They think you're going to invite them to dinner or even more often they think it's an invasion of privacy.

\subsection{Say Goodbye}

"See you." "Have a good day! To express good will. Chinese people like to say "slow walk", "welcome to come again", "please stay" and so on. But many Chinese do not know how to express this authentic Chinese farewell in English. These differences are caused by differences in cultural backgrounds. 


\subsection{The Mistake of Giving Thanks}

Chinese people usually do not care about politeness when they are close, so they rarely use the word "thank you" among acquaintances. But foreigners believe that people are born equal, even between superiors and subordinates, between elders and junior, and between lovers should express their gratitude.

These failures of non-verbal behaviors indicate that the students' overall pragmatic communication ability is low, which causes considerable obstacles to the students' communication. Therefore, we should pay enough attention to the study of students' pragmatic failures in verbal communication. After all, it is of great significance for the development of cross-cultural communication and foreign language teaching.

\section{Enlightenment and Suggestions on College English Teaching}

With the development of The Times, the teaching of college English classes should also keep pace with The Times, constantly explore the teaching mode to meet the requirements of The Times, break through the traditional teaching methods, and avoid the tendency of only paying attention to the language knowledge rather than the use of language. In view of the characteristics of today's social development, college English language teaching should strengthen the cultivation of students' practical pragmatic ability to achieve a qualitative leap in teaching.

\subsection{Teach Students Cultural Knowledge, Cultivate and Improve Students' Awareness and Ability of Intercultural Communication}

Differences in cultural backgrounds lead to great differences in the use of different languages. The process of language communication is a process of cultural collision and integration. The two interact and influence each other. Therefore, language teaching should be culturally oriented and constantly strengthen the cultivation of cultural factors. For example, if students do not understand western culture, they will find it difficult to understand.

He told me under the rose.

In this case, under the rose means "under the rose". The significance of privately confidentially, it derives from the ancient Greek myth and become the European custom. In ancient Greek mythology, Eros was the son of Aphrodite, goddess of love and beauty. In defense of her mother's reputation, the little Cupid sent a bouquet of roses to the silent god Harpocrates, asking him to keep quiet about Aphrodite. When the god of silence accepts the rose, he is silent, keeping the goddess's secret. Ancient Greek culture is the origin of European civilization, and the cultural fashion in fairy tales has deeply influenced the customs of the whole Europe. Therefore, when people visit and see roses painted on top of the table of the host family, the guests will understand that all the behaviors mentioned on the table should not be published. The Latin for "under the rose" is Sub Rosa and the German is under Rosen.

It can be seen that in the process of English teaching, we should not only teach students the language level, but also teach students the corresponding cultural background knowledge and customs, so as to better help them build their awareness of intercultural communication and improve their pragmatic ability.

how should teachers consciously input students' cultural knowledge in college English classes? Firstly, it systematically introduces students to the cultural background, cultural customs, cultural differences and similarities between eastern and western cultures in combination with the textbook, so that students can understand the social culture of English-speaking countries, so that they can accurately understand and use the language. For students do not understand or are not familiar with English language communication behavior, such as greeting, apology, say "hello", shows that the interpretation of the teacher must promptly by contrast the methods of use of Chinese and let students understand the differences between them, after students have a clear cognition will learn knowledge to practical operations, and in the process of the accumulation of learning cultivate their sensitivity to the foreign culture. 
At the same time, we use various methods to cultivate students' awareness and ability of intercultural communication. For example, students are encouraged to communicate with foreigners frequently in their lives, get more contact with foreign literary works and film and television works, apply the language they learn to real life and constantly compare the differences between eastern and western pragmatics, so as to reduce the pragmatic failures in cross-cultural communication. in the classroom, teachers can adopt the "role playing" method to help students master the awareness and method of how to use language in an effective way with the cultural background, so as to teach through lively activities.

\subsection{Teachers Should Improve Their Pragmatic and Intercultural Communication Skills}

The work of a teacher means teaching by words and deeds. If a teacher's own pragmatic ability is not qualified, it will have a great impact on the students he cultivates. For most foreign language teachers in China, their knowledge mainly comes from the learning under the traditional teaching mode and the accumulation in the practice process. Since they have no experience of going abroad, they cannot talk about receiving the formal training of intercultural communication courses. Therefore, as the knowledge imparter, teachers should study some books with theoretical guidance in terms of pragmatic ability, constantly improve their theoretical level and guide their practice with theories. At the same time, we should learn and read more materials that can reflect the politics, economy, culture, customs, art and other contents of English-speaking countries to expand our knowledge and verify the theory with practice. Popular, which can reflect the contemporary language to constantly learning, such as the Oxford English dictionary in the selection of the word of the year in 2013, including selfie (take), budget the wife/husband, economy applicable female/male), phubber (down), bromeo (bromeo), fangirl/fanboy fans), a (gayriage (same-sex marriage), mom petition (child), social mercifully (interpersonal bubble), Showrooming, Abenomics and other new words in English. Therefore, the quality of teachers will directly affect the improvement of students' pragmatic ability. In teaching practice, to master or experience about English culture background knowledge to students, and how to guide students in the learning process of constantly accumulating this knowledge, the cultural differences of language knowledge into teaching, to make students truly understand their cross-cultural communication problems, help the non-English major students in English learning and the actual communication level achieve overall improvement.

\section{References}

[1]. Chomskv, N. (1962). Explanatory Models in Linguistics. In: Negal E,Suppes P, tarski A(Eds.). Logic, Methodology and Philosophy of Science(pp.528 - 550). Standford University Press.

[2]. Thomas, J. (1983). Cross cultural Pragmatic failure. Applied Linguistics, 4/2:91-112.

[3]. Levinson, S.C. (1983). Pragmatics. Cambridge: Cambridge University Press.

[4]. Widdowson, H. G (2000). Linguistics. Shanghai Foreign Language Education Press \&Oxford University Press.

[5]. Thomas, J. Cross-cultural pragmatic failure [J], Applied Linguistics, 1983: 61-67. 